\title{
Article \\ Numerical Simulation of the Evacuation Process in a Tunnel during Contraflow Traffic Operations
}

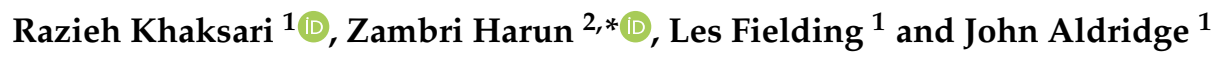 \\ 1 London Bridge Associates Ltd., Surbiton, London KT6 4TS, UK; barankhaksari@lba.london (R.K.); \\ lesfielding@lba.london (L.F.); johnaldridge@lba.london (J.A.) \\ 2 Faculty of Engineering and Built Environment, National University of Malaysia, UKM, Bangi 43600, Malaysia \\ * Correspondence: zambri@ukm.edu.my; Tel.: +60-3-8911-8390
}

Citation: Khaksari, R.; Harun, Z.; Fielding, L; Aldridge, J. Numerical Simulation of the Evacuation Process in a Tunnel during Contraflow Traffic Operations. Symmetry 2021, 13, 2392. https://doi.org/10.3390/sym13122392

Academic Editors: Xiaolei Zhang, Wei Tang, Jianping Zhang, Qiang Wang and Xiaochun Zhang

Received: 4 November 2021

Accepted: 25 November 2021

Published: 11 December 2021

Publisher's Note: MDPI stays neutral with regard to jurisdictional claims in published maps and institutional affiliations.

Copyright: (c) 2021 by the authors. Licensee MDPI, Basel, Switzerland. This article is an open access article distributed under the terms and conditions of the Creative Commons Attribution (CC BY) license (https:// creativecommons.org/licenses/by/ $4.0 /)$.

\begin{abstract}
The purpose of this numerical research is to assess the evacuation process in a tunnel under the contraflow condition. Numerical simulations utilizing FDS+Evac codes associated with a fire dynamic simulator (FDS) model simulating a fire scenario are used to simulate evacuation and to predict the impact of a $100 \mathrm{MW}$ fire scenario on the occupants inside the tunnel. Traffic and passenger conditions are based on real data from a tunnel in the UK. Two fire loads, $100 \mathrm{MW}$ and $5 \mathrm{MW}$, are studied to represent an HGV and a passenger car fire. The $100 \mathrm{MW}$ fire source, caused by an unexpected heavy good vehicle (HGV) catching fire, is located in the middle of the tunnel and at $20 \%$ of tunnel length to study the effect of fire source location on the usage of emergency exits and tenability thresholds. The dimensions and the inclination angle of the existing roadway tunnel are $1836 \mathrm{~m}(\mathrm{~L}) \times 7.3 \mathrm{~m}(\mathrm{~W}) \times 5 \mathrm{~m}(\mathrm{H})$ and $4 \%$, respectively. It should be noted that the $4 \%$ inclination of the tunnel causes asymmetry propagation of smokes thus the visibility of the downstream and upstream from the fire behave differently. The maximum needed time to evacuate using all egress, the amount of fractional effective dose and visibility at the human's height are analyzed. Simulation results indicate that when a realistic worst-case fire scenario is modeled, all evacuees can survive before the combustion gases and heat influence their survivability.
\end{abstract}

Keywords: tunnel fire; evacuation process; fire dynamic simulator

\section{Introduction}

The role that road tunnels play in the urban transit system has been more significant especially with the development of society. Therefore, more and more tunnels have been constructed. However, tunnels are vulnerable to fire and frequent tunnel fire accidents happen accidentally and deliberately. For example, Tauern tunnel fire (1999), Mont Blanc tunnel fire (1999), Stanford Salzburg tunnel (2000), St. Gotthard tunnel fire (2001) caused severe damages to users, tunnel infrastructure, traffic, and environment. Fire scenarios in tunnels are very different from fires in compartments since tunnels are longer, and fire loads such as lorries can lead to very serious fires up to $200 \mathrm{MW}$. Moreover, traffic may be forced to a complete stall in the tunnel. Consequently, it is vital to design a tunnel that can resist a severe fire incident and allows for the secure evacuation of trapped users and effective firefighting. The evacuation process in the case of tunnel fire is a complex situation that various parameters such as tunnel characteristics and human behaviour affect it. It is obvious that determining parameters related to occupants' behaviour is not straightforward due to their natural variability presented in the research as their behavioural uncertainty [1,2]. The effects of these factors on the process of egress models analyzed by [3,4]. Based on studies carried out by [5-9], the evacuation performance is affected by the evacuation time and the exit choice. In addition, Fridolf's study [10] showed that the occupants' safety is affected by consequences of the fire event such as the spread of toxic gases and reduced visibility due to smoke. Another factor that affects the evacuation process is the tunnel structure strength in case of tunnel fire which is influenced by maximum temperature beneath the tunnel ceiling. 
Haddad et. al. [11] carried out a series of small-scale tunnel fire experiments to study to examine the temperature distribution along the tunnel ceiling. The smoke maximum temperature has been investigated experimentally and theoretically beneath the tunnel ceiling and a theoretical estimation model for predicting maximum gas temperature under the ceiling was proposed. Then, the results from the theoretical equation were compared with experimental data and an acceptable prediction was presented. During the last 10 years, the use of computer models to simulate the evacuation process has increased as numerical models can combine both fire dynamics and evacuation process [9]. These models are the most feasible and economic way to analyze and study the fire phenomenon and its basic parameters in different conditions as well as the egress process under the fire effects. Currently, there are various computer models such as zone models, and computational fluid dynamics (CFD) models. Since fire is a very complicated phenomenon including radiation, combustion, and fluid dynamics, CFD modeling which requires details of tunnel construction, and initial and boundary conditions, could be a good choice to simulate air and exhaust gas flows and occupants' egress as well. Several specific characteristics of tunnel fire, such as its HRR and smoke and their effects [12-16], and modelling of the evacuation of people in the tunnel $[15,17-19]$ were studied in the literature. Haddad et al. (2016) [20] studied the importance of backlayering in CFD simulation using OpenFOAM of an unexpected fire occurring in a one-way underground rail system called mass rapid transit (MRT) with a $2.266 \mathrm{MW}$ fire. In this study, various parameters such as buoyancy and critical velocity were highlighted. Fire Dynamic Simulator (FDS) is a CFD model commonly used for various types of fire engineering problems. FDS is developed by the National Institute of Standards and Technology (NIST), has been verified as a reliable tool by several tests and experiments in the references [21,22]. FDS was used in McGrattan's study [15] to simulate tunnel fire numerically. In this study, the peak gas and surface temperature, which was approximately $500{ }^{\circ} \mathrm{C}$ when averaged over the length of the tunnel, was quantified. The influence of ventilation on fire growth and peak heat release rate in tunnels has been analyzed [23]. Halawa [24] used FDS to propose the "stratification velocity" during a tunnel fire evacuation. This proposed velocity can maintain the stratification of smoke downstream. In his numerical study, the stratification velocity is less than the critical velocity in most cases. Although, according to this study, the use of critical velocity can prevent the spread of smoke upstream and also maintain good smoke stratification downstream in the case of a small HRR. Guo et al. [25] used FDS to simulate fires in an inclined metro tunnel. They analyzed CO concentration, visibility, and temperature. They found out that the risk of tunnel fire is related to the gradients and the location of the fire. The risk with a positive gradient was lower than a negative gradient. Although, it was changed after the location of the fire changed.With regards to pedestrian evacuation, human behaviour was simulated in a variety of models. One of the researchers who studied pedestrian dynamics is Burstedde et al. (2001) [26] who used a two-dimensional cellular automaton model. The social force model was considered in [27]. In addition to those difficult models mentioned above, other program languages such as $\mathrm{C}++$ have been used to simulate personnel evacuation. One of these models is FDS+Evac. Ref. [28] carried out numerical simulation by FDS+Evac model to study the effects of emergency exits and staircase characteristics on human evacuation in a dormitory [28]. In 2013, Lei again studied the influence of two key parameters on the evacuation process for a dormitory in China by FDS+Evac [29]. Ronchi et al. (2013) assessed road tunnel safety through analyzing the results of various evacuation models including FDS+Evac, pathfinder [19]. The evacuation safety was assessed by Yamamoto et al. [30] via a numerical simulation of a tunnel fire. In this study, a longitudinal ventilation system with jet fans was used to study the evacuation time in smoky conditions. The results of this study indicate that when ventilation was controlled and jet fans'velocity was not more than a certain value, the evacuation time was prolonged as the flow of smoke could not be controlled. In this study, Fire Dynamics Simulator (FDS 6.7.5) and FDS+Evac are used to simulate $100 \mathrm{MW}$ and $5 \mathrm{MW}$ fire scenarios in a tunnel with $1800 \mathrm{~m}$ length, $7.3 \mathrm{~m}$ width, and $5.2 \mathrm{~m}$ height. $100 \mathrm{MW}$ fire was simulated at two different locations to 
study the effect of fire source location on emergency exit choice by evacuees. Our academic background in numerical and experimental studies of fire scenarios in different conditions and environments $[31,32]$ is used in this research to particularly evaluate the ability of the FDS+Evac to simulate the evacuation process. Real case scenarios are used i.e., drivers, as well as passengers, are inside the vehicles and vehicles queue in two lanes. Fire simulation, as well as evacuation process modeling, are utilized to evaluate the users' safety in case of a fire scenario in a tunnel with actual dimensions when the ventilation system is turned off and the tunnel is under contraflow operation mode. The novelty of this study is simulation passengers inside the vehicles instead of adjacent to the vehicles which results in more accurate evacuation time. The results show people's evacuation process, the prediction of pedestrian flows, and the possibility to save them from fire hazards.

\subsection{FDS}

The FDS [33] developed by NIST, is a high-performance CFD model applied to simulate fire scenarios in varied environments. FDS solves the Navier Stokes equations including the conservation mass, species, and momentum, appropriate for low-speed, thermally driven flow with an emphasis on smoke and heat transport from fire numerically $[33,34]$. FDS uses rectangular meshes compartmentalizing the computational domain, to solve the equations numerically in every mesh. The FDS model counts velocity, temperature, gas density, pressure, and species concentrations in each cell. Large-eddy simulation (LES) turbulence modeling is utilized and the emphasis is on smoke and heat transfer from fires. The FDS package has a visualization tool, named Smokeview, capable of providing a 3D simulation of FDS results, fire and smoke propagation, and 2D slices of chosen variables and shows the pictorial results in the form of pictures.

\subsection{FDS+Evac}

The evacuation model of FDS is Evac [35], which is an agent-based evacuation module. The movement and behaviour of evacuees are modeled via a corrected Helbing's social force model in FDS+Evac $[27,36,37]$. There are other model such as Pathfinder which is an agent based evacuation model and also able to couple fire development and evacuees' behavior to some degree. The results derived from the evacuation simulation in the tunnel could be distorted by such misrepresentation. In this evacuation model, each agent is considered independently and his/her personal properties and escape strategies characterize his/her evacuation. Both physical and psychological forces were applied to model the movement of each evacuee. FDS can simulate fire and smoke spread and the effect of fire scenario on the evacuation process and evacuees' decision-making as well. The data from fire and smoke simulation in each cell at each time step of the calculation is considered in this model and then the effects of simulated fire characteristics on evacuees' movement, choice of an escape route, and visibility of exits are used to model agent's behaviour. A corrected model of Purser's FED (Fractional Effective Dose) model [38] is applied in FDS+Evac to model people intoxication and incapacitation during the evacuation. The benefit of tunnel fire numerical simulation of tunnel evacuation via FDS+Evac is the direct connection between the evacuation module and the fire data derived from the fire simulation. The tunnel emergency exits characteristics and the effect of fire and traffic on the evacuation process are illustrated in this study.

\section{Materials and Methods}

\subsection{Modelling of Fire}

Radiation, turbulence and combustion are the essential physical mechanisms in a fire. Governing equations including the continuity equation, the momentum equation, and the energy equation are solved considering relevant models. These governing equations are solved in special, highly simplified cases. A numerical approach is used to solve these governing equations based on Computational Fluid Dynamics (CFD). The significant stages of carrying out a CFD simulation are: definition of the physical models, identifying the 
problem geometry, and creating the mesh. In FDS, the Navier-Stokes equations which are devoted for low speed, thermally-driven liquid are used and the emphasis is on smoke and heat transport from fires. Conservation equations for mass, momentum, and energy with the equation of state are used to formulate the process of fire growth and spread [33]. Equations (1)-(4) present the conservation of mass, species, and momentum as well as the equation of state solved by FDS. Conservation of mass:

$$
\frac{\partial \rho}{\partial t}+u \cdot \nabla \rho=-\rho \nabla \cdot u
$$

where $\frac{\partial \rho}{\partial t}$ is the density change over time and $\mathrm{u}$ is the velocity vector. Conservation of momentum:

$$
\frac{\partial \rho u}{\partial t}+\nabla p u=-\nabla p+\rho f+\nabla \tau_{i j}
$$

where $p$ represents pressure, $\tau_{i j}$ is the stress tensor, and $\frac{\partial \rho u}{\partial t}$ and $\nabla p u$ define the rate of change of momentum, and the force term $f$ in the momentum equation represents external forces such as the drag exerted by liquid droplets. Conservation of species:

$$
\frac{\partial \rho h_{\alpha}}{\partial t}+u \cdot \nabla \rho h_{\alpha}=-\rho \cdot h_{\alpha} \nabla \cdot u+\nabla \cdot \rho D_{\alpha} \nabla Y_{\alpha}+m^{\prime \prime \prime},
$$

where $h_{\alpha}$ is the mass fraction of species $\alpha, D_{\alpha}$ is the diffusion coefficient, and $m^{\prime \prime \prime}$ represents the mass production rate of species per unit volume [39] The equation of state is:

$$
p=\rho R T \text {. }
$$

Smokeview is the second part of the package for visualization of the results computed by FDS.

\subsection{Modeling of Evacuation}

FDS+Evac which is the evacuation segment of FDS can model the influence of the fire scenario on occupants' behaviour, the way they escape and travel through evacuation path [35]. In this model, although a detailed algorithm is used taking into account physical forces which result in 'social' forces, each evacuee is characterized independently. One of the main starting points to have a high level of reality of the evacuation simulation is the sub-model of social behaviour. Although the available group behaviour sub-models require further experimental validation [40]. How much users are familiar with emergency exits, the visibility of exits, and the influence of smoke and combustion products affect the agents' escape strategies. As FDS+Evac uses an accidental way to develop the initial locations and characteristics of the agents, it is predictable that FDS+Evac does not obtain the same results if several simulations are carried out for the same FDS+Evac input file [2]. The strongest point of FDS+Evac is the interplay between fire simulation and evacuation simulation where Evac has direct access to the fire simulation results. The FED (Fractional Effective Dose) parameter is implemented to find out whether tunnel evacuees can survive under certain simulated conditions.

\subsection{Fractional Effective Dose (FED)}

Fractional effective dose, so-called FED is applied in the FDS+Evac model to evaluate occupants' response to toxic exposure. The $\mathrm{CO}_{2}$ concentration is considered here exclusively concerning faster than normal breathing (hyperventilation). $\mathrm{CO}_{2}$ is an unbreathable gas and would cause acidosis in human body however it is not assumed that the $\mathrm{CO}_{2}$ concentration would be so high. Purser developed the Fractional Effective Dose index 
(FED) to measure human incapacitation because of combustion products [38]. The FED is calculated by Equation (5).

$$
\mathrm{FED}_{\text {tot }}=\left(\mathrm{FED}_{\mathrm{CO}}+\mathrm{FED}_{\mathrm{CN}}+\mathrm{FED}_{\mathrm{NO}_{\mathrm{X}}}+\mathrm{FLD}_{\text {irr }}\right) \times \mathrm{HV}_{\mathrm{CO}_{2}}+\mathrm{FED}_{\mathrm{O}_{2}} .
$$

$\mathrm{CO}$, which is the most important narcotic fire gas, is directly additive (Purser and Grimshaw (1984)). Its toxicity depends upon the dose accumulated in the blood and presents a serious hazard at concentrations of approximately $100 \mathrm{PPM}$ and above [38]. FED $\mathrm{CO}_{\mathrm{C}}$ is calculated as:

$$
\mathrm{FED}_{\mathrm{CO}}=\int_{0}^{t} 2.764 \times 10^{-5} \mathrm{C}_{\mathrm{CO}}(t)^{1.036} d t
$$

where $\mathrm{C}_{\mathrm{CO}}$ is the $\mathrm{CO}$ concentration (PPM) and $t$ is time in minutes. $\mathrm{FED}_{\mathrm{CN}}$ is calculated as:

$$
\operatorname{FED}_{\mathrm{CN}}=\int_{0}^{t}\left(\frac{1}{220} \exp \left(\frac{\mathrm{C}_{\mathrm{CN}}(t)}{43}\right)-0.0045\right) d t,
$$

where the protective effect of $\mathrm{NO}_{2}$ is correlated by hydrogen cyanide (HCN) concentration (PPM). $\mathrm{C}_{\mathrm{CN}}$ is calculated as:

$$
\mathrm{C}_{\mathrm{CN}}=\mathrm{C}_{\mathrm{HCN}}-\mathrm{C}_{\mathrm{NO}_{2}}-\mathrm{C}_{\mathrm{NO}} \text {. }
$$

The fraction of an incapacitating dose of $\mathrm{NO}_{\mathrm{x}}$ is calculated as:

$$
\mathrm{FED}_{\mathrm{NO}_{\mathrm{x}}}=\int_{0}^{t}\left(\frac{\mathrm{C}_{\mathrm{NO}_{\mathrm{x}}}(t)}{1500}\right) d t
$$

where sum of $\mathrm{NO}$ and $\mathrm{NO}_{x}$ concentrations (PPM) is presented as $\mathrm{C}_{\mathrm{NO}_{x}}$. The Fractional Lethal Dose (FLD) of irritants is calculated as:

$$
\begin{array}{r}
\mathrm{FLD}_{\mathrm{irr}}=\int_{0}^{t}\left(\frac{\mathrm{C}_{\mathrm{HCI}}(t)}{F_{\mathrm{FLD}, \mathrm{HCI}}}+\frac{\mathrm{C}_{\mathrm{HBr}(t)}}{F_{\mathrm{FLD}, \mathrm{HBr}}}+\frac{\mathrm{C}_{\mathrm{HF}(t)}}{F_{\mathrm{FLD}, \mathrm{HF}}}\right. \\
\left.+\frac{\mathrm{C}_{\mathrm{SO}_{2}}(t)}{F_{\mathrm{FLD}, \mathrm{SO}_{2}}}+\frac{\mathrm{C}_{\mathrm{NO}_{2}}(t)}{F_{\mathrm{FLD}, \mathrm{NO}_{2}}}+\frac{\mathrm{C}_{\mathrm{C}_{3} \mathrm{H}_{4} \mathrm{O}}(t)}{F_{\mathrm{FLD}, \mathrm{C}_{3} \mathrm{H}_{4} \mathrm{O}}}+\frac{\mathrm{C}_{\mathrm{CH}_{2} \mathrm{O}(t)}}{F_{\mathrm{FLD}, \mathrm{CH}_{2} \mathrm{O}}}\right) d t,
\end{array}
$$

where the instantaneous concentrations (PPM) of each irritant are the nominators and the exposure doses of respective irritants predicted to be lethal to half the population are the denominators are The lethal exposure doses $\left.\left(\mathrm{F}_{\mathrm{FLD}}\right)\right)(\mathrm{PPM} \times \mathrm{min})$ from [38] are given in Table 1.

Table 1. Coefficients used for the computation of irritant effects of gases.

\begin{tabular}{ccccccc}
\hline $\mathbf{H C I}$ & $\mathbf{H B r}$ & $\mathrm{HF}$ & $\mathbf{S O}_{2}$ & $\mathbf{N O}_{2}$ & $\mathbf{C}_{3} \mathbf{H}_{4} \mathbf{O}$ & $\mathbf{C H}_{2} \mathbf{O}$ \\
\hline 114,000 & 114,000 & 87,000 & 12,000 & 1900 & 4500 & 22,500 \\
\hline
\end{tabular}

Low oxygen exposure can cause hypoxia. When $\mathrm{O}_{2}$ concentration decreases toward $10 \%$, narcotic intoxication with lethargy, and sometimes euphoria rapidly occurs. This is followed by unconsciousness, and a critical value of $9.6 \% \mathrm{O}_{2}$ will be used in FDS [41-43]. The FED of low $\mathrm{O}_{2}$ hypoxia is calculated as:

$$
\mathrm{FED}_{\mathrm{O}_{2}}=\int_{0}^{t} \frac{1}{\exp \left(8.13-0.54\left(20.9-\mathrm{C}_{\mathrm{O}_{2}}(t)\right)\right.} d t,
$$

where $\mathrm{CO}_{2}$ is the concentration. The rate of uptake of $\mathrm{CO}$ is increased when $\mathrm{CO}_{2}$ concentration increases. Moreover, it is itself a narcotic and acts independently of the effect of the other gases [44]. When the concentration of $\mathrm{CO}$ reaches $5 \%$, breathing is strongly stimulated 
and at $7-10 \%$ unconsciousness occurs after a few minutes $[45,46]$. The hyperventilation factor produced by carbon dioxide is calculated as:

$$
\mathrm{HV}_{\mathrm{CO}_{2}}=\frac{\exp \left(0.1903 \mathrm{C}_{\mathrm{CO}_{2}}(t)\right)+2.0004}{7.1} .
$$

\section{Description of Tunnel Model and Evacuation Scenarios}

\subsection{Road Tunnel Model}

The level of complexity of tunnel fire simulation is very high. Consequently, appropriate design procedures and simulation models should be used to carry out numerical simulation projects such as tunnels, roads or railway structures. In this study, computer modeling is used to assess fire safety in road tunnels. The effectiveness and efficiency of FDS+Evac are evaluated via a practical case. Tunnel fires are very different from fires within compartments because of their specific construction. In addition, there is a possibility of large fire loads in tunnels, such as HGV fires, create very severe fires of 50 MW or 100 MW HRR. Therefore, it is required that every tunnel has a resistant structure to withstand the effects of a realistic worst-case fire and allows safe evacuation and effective fire-fighting. FDS+Evac simulation was utilized in this research to evaluate a predictable and reasonable worst-case scenario (100 MW fire in the middle of the tunnel) in addition to a $5 \mathrm{MW}$ fire in the middle of the tunnel and $100 \mathrm{MW}$ fire close to the tunnel portal, considering the specific infrastructure construction features of the tunnel under investigation. FDS+Evac numerical simulation has two main sections in order to simulate an evacuation scenario. The first section is the determination of tunnel structure and assigning specific boundary conditions. In the second step, the number and characteristics of the evacuees are determined. The dimensions of tunnel and traffic conditions are based on actual dimensions and real data however the details have to be withheld. The investigated tunnel is approximately $1.8 \mathrm{~km}$ long and consists of two tunneled roadways. The rectangular cross-section dimension inside the horseshoe shape is $7.3 \mathrm{~m}$ wide and $5.2 \mathrm{~m}$ high. It has two lanes of unidirectional traffic during normal operation, while under contraflow condition one bore is closed for maintenance or an incident. Tunnel structure including a curved crown and vertical walls is constructed via FDS orthogonal obstacles built by OBSTRUCTION parameter in FDS composed of concrete with the $10 \mathrm{~cm}$ thickness which is defined by THICKNESS parameter in FDS. There are 16 emergency cross passages located at approximately $100 \mathrm{~m}$ intervals to enable tunnel users to cross into the non-incident tunnel in the event of a fire emergency. This interval between emergency exits is chosen to comply with United Kingdom's legislation. Besides the geometry, FDS requires inputs for the three-dimensional cell size, the fire source position, fuel type, HRR, the thermal properties of walls, exit doors, vehicles, and boundary conditions. The calculation time and the accuracy of the results rely on the mesh fineness in FDS. A non-dimensional expression $D^{*} / d x$ is defined to evaluate the grid resolution. $d x$ is the nominal size grid $[\mathrm{m}]$ and $D^{*}$ is defined as below:

$$
D^{*}=\left(\frac{Q}{\rho_{0} * c_{p} * T_{0} * \sqrt{g}}\right)(0.4),
$$

where $Q$ is HRR[W], $\rho_{0}$ is ambient density, $T_{0}$ is ambient temperature, and $c_{p}$ is the specific heat of ambient. An adequate resolution is obtained when $D^{*} / d x$ is between 4 and 16 [47]. Based on this, the 'fire' section had cells with dimensions $0.25 \mathrm{~m} \times 0.2 \mathrm{~m} \times 0.25 \mathrm{~m}$ for $100 \mathrm{MW}$ and $0.2 \mathrm{~m} \times 0.2 \mathrm{~m} \times 0.25 \mathrm{~m}$ for $5 \mathrm{MW}$. This section has a length of $40 \mathrm{~m}$. Mesh size of $0.5 \mathrm{~m} \times 0.2 \mathrm{~m} \times 0.25 \mathrm{~m}$, which is coarser, covers the rest of the tunnel dimensions. In addition to the above evaluation, a mesh sensitivity analysis carried out to compare $0.2 \mathrm{~m}, 0.25 \mathrm{~m}$, and $0.4 \mathrm{~m}$ meshes in the fire source location ( $40 \mathrm{~m}$ in the middle of tunnel) for $100 \mathrm{MW}$ fire and $0.1 \mathrm{~m}, 0.2 \mathrm{~m}$, and $0.4 \mathrm{~m}$ meshes in the fire source location $(30 \mathrm{~m}$ in the middle of tunnel) for $5 \mathrm{MW}$ fire. According to the results of mesh analysis for HGV fire, the difference between measured temperature at $300 \mathrm{~s}$ in $0.25 \mathrm{~m}$ and $0.4 \mathrm{~m}$ is between $4 \%$ and $5 \%$ while it is between $10 \%$ and $15 \%$ in $0.25 \mathrm{~m}$ and $0.2 \mathrm{~m}$ mesh size and the difference 
between measured temperature at $800 \mathrm{~s}$ in $0.2 \mathrm{~m}$ and $0.4 \mathrm{~m}$ is between $15 \%$ and $20 \%$ while it is between $2 \%$ and $2.5 \%$ in $0.2 \mathrm{~m}$ and $0.1 \mathrm{~m}$ mesh size for $5 \mathrm{MW}$ fire (Figure 1 ). As a result, $0.25 \mathrm{~m}$ mesh size was chosen for the fire source location. The same analysis carried out for passenger car (PC) fire source as well. The total simulation time is set as $780 \mathrm{~s}$. A $2 \mathrm{D}$ computational mesh with $0.5 \mathrm{~m}$ cell length is assigned for evacuation calculation. The ambient temperature in the tunnel is assumed to be $13.3^{\circ} \mathrm{C}$. The upward slope of $4 \%$ is accounted in the model by changing the gravity vector along the length. In this part of town, 5.8 months of the year has the windiest days with an average speed of more than 18.5 kilometer per hour $(\mathrm{km} / \mathrm{h})$, it lasts from October 12 to April 4 . This wind velocity is defined via pressure differences between portals. The effect of air movement caused by the movement of vehicles within the tunnel is ignored due to the low speed of vehicles, $20 \mathrm{~m} / \mathrm{s}$, in the contraflow operation and thus has not a significant impact on the smoke movement. Apart from the ventilation fan installation base, no more equipment is installed in the tunnel. The length of the computational domain is lengthened $3 \mathrm{~m}$ at each portal to simulate the exhaust of smoke to the environment. These extended domains have an open boundary condition.
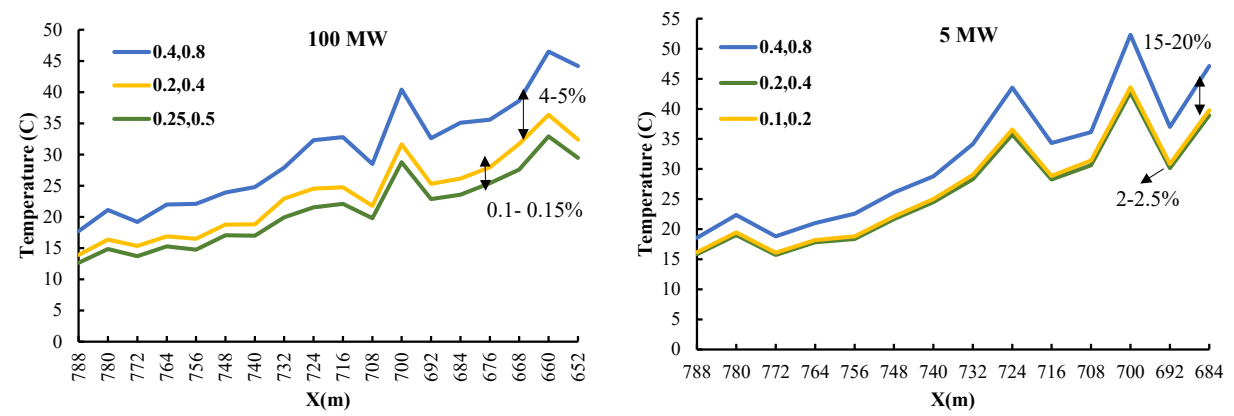

Figure 1. Comparison of temperature measured at human's height between for $100 \mathrm{MW}$ and $5 \mathrm{MW}$ fires.

\subsubsection{The First Scenario}

Based on [48-50], a fully-laden HGV fire with $100 \mathrm{MW}$ fire heat release rate and an ultra-fast growth rate is considered in the first scenario. The source of fire is represented by a $42.5 \mathrm{~m}^{2}(17 \mathrm{~m} \times 2.5 \mathrm{~m})$ plate placed about $1.3 \mathrm{~m}$ above the tunnel floor in the middle of the structure. The fire load follows an ultra fast $t$-squared $\left(t^{2}\right)$ graph with $\alpha=0.1876$ which means it has a relationship proportional to time squared, which is for flaming and radially spreading fires. The heat release rate reaches a maximum of $100 \mathrm{MW}$, which was predictable in a scenario without a suppression system.

\subsubsection{The Second Scenario}

The fire load is the same as the first scenario's fire load but the fire is located at $20 \%$ of tunnel length.

\subsubsection{The Third Scenario}

The source of fire is a passenger car with $5 \mathrm{MW} \mathrm{HRR}$ and an ultra-fast growth rate is considered. The source of fire is a $4.5 \mathrm{~m} \times 1.7 \mathrm{~m}$ plate placed about $1.3 \mathrm{~m}$ above the tunnel floor in the middle of the tunnel.

Figure 2 shows a graphical view of the tunnel for the first scenario. 


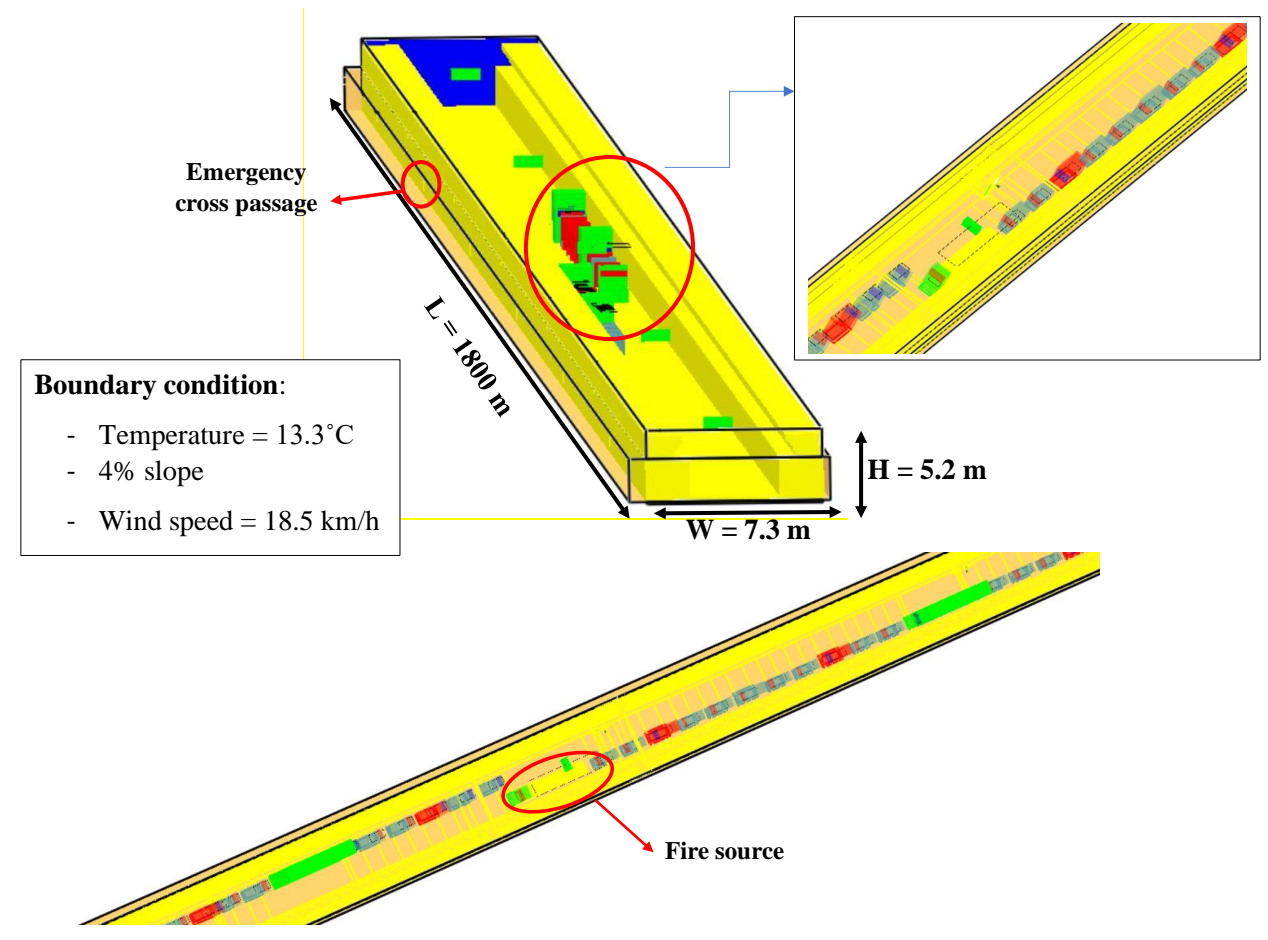

Figure 2. Graphical view of the tunnel under study.

\subsection{Sensors}

A wide range of observed values such as temperature, thermal flow, flow velocity, and visibility can be measured by FDS. In this simulation, visibility, FED are measured. This measurement was recorded at the fire centre point and continue with $8 \mathrm{~m}$ intervals and at the heights of $1.8 \mathrm{~m}$ above the level of the escape walkway to assess tenability levels, and potential danger to evacuating persons. The tenability thresholds and visibility limits are provided in Table 2.

Table 2. The tenability thresholds and visibility limits.

\begin{tabular}{cccc}
\hline $\mathbf{C O}$ & $\mathbf{C O}_{2}$ & $\mathbf{N O}_{2}$ & Visibility \\
\hline $1200 \mathrm{ppm}$ & $40,000 \mathrm{ppm}$ & $1 \mathrm{ppm}$ & $10 \mathrm{~m}$ \\
\hline
\end{tabular}

\subsection{Evacuation Scenario}

An evacuation scenario was specified in addition to the fire scenario described above. The novelty of this project is considering drivers inside vehicles whereas they were usually simulated beside vehicles. In this way, the time needed to leave vehicles is considered and the simulation is more realistic. The number of evacuees in this fire simulation was determined based on the traffic density, the type of vehicles, and the number of passengers present in each vehicle with the assumption of one passenger in each vehicle. The tunnel carries an average annual daily traffic volume of approximately 24,175 (Northbound) and 23,005 (Southbound). The proportion of each vehicle type traveling in either direction through the tunnel is summarised in Table 3.

Table 3. The proportion of each vehicle type.

\begin{tabular}{ccc}
\hline Vehicle Type & Northbound & Southbound \\
\hline Passenger car & $58.5 \%$ & $86.8 \%$ \\
Van & $32.2 \%$ & $7.1 \%$ \\
HGV & $9.3 \%$ & $6.0 \%$ \\
\hline
\end{tabular}


The average distance between vehicles is $8 \mathrm{~m}$. It was assumed that vehicles were located at one-half of the tunnel length in each lane because cars located after the fire source (in the direction of travel) can continue driving, and then the second half of the tunnel length would be empty. Regarding the tunnel inclination and the stack effect, it is expected that evacuees may be exposed directly to the combustion products and toxic fumes. Based on average daily traffic and the closure time of $2 \mathrm{~min}$ in case of fire, the number of each type of vehicle and the number of people queuing behind the fire source were calculated. The number and type of vehicles and evacuees are shown in Table 4 (Northbound) and Table 5 (Southbound).

Table 4. The number of each vehicle type and the number of people (Northbound).

\begin{tabular}{cccc}
\hline Vehicle Type & Number & Occupancy & People \\
\hline Passenger car & 20 & 1 & 20 \\
Van & 11 & 1 & 11 \\
HGV & 3 & 1 & 3 \\
Total & & & 34 \\
\hline
\end{tabular}

Table 5. The number of each vehicle type and the number of people (Southbound).

\begin{tabular}{cccc}
\hline Vehicle Type & Number & Occupancy & People \\
\hline Passenger car & 28 & 1 & 28 \\
Van & 2 & 1 & 2 \\
HGV & 2 & 1 & 2 \\
Total & & & 32 \\
\hline
\end{tabular}

The occupancy of each type of vehicle was assumed to be 1 to simplify the simulation. A standard dimensions of vehicles of $4.7 \mathrm{~m} \times 1.7 \mathrm{~m} \times 1.7 \mathrm{~m}$ for passenger vehicles, $5.33 \mathrm{~m}$ $\times 1.7 \mathrm{~m} \times 2.3 \mathrm{~m}$ for vans, and $19 \mathrm{~m} \times 2.5 \mathrm{~m} \times 4.3 \mathrm{~m}$ for heavy vehicles $(\mathrm{L} \times \mathrm{W} \times \mathrm{H})$ were considered in the scenarios. It is assumed that the sum of detection time and pre-movement time is $150 \mathrm{~s}$, which is based on the actual detection time in this sample tunnel (60 s) and the sum of response and recognised time by evacuees. In addition, the default "Adult" agent type was used in FDS+Evac calculations.

\section{Results}

Based on [3], evacuation models have different degrees of sophistication. The usability of various evacuation models (FDS+Evac 2.3.1, STEPS 4.1, Pathfinder 2011, and Simulex 5.8) and their characteristics were studied in [18]. Factors and parameters influencing human behaviour during the evacuation process are evaluated in this analysis based on the provided description and practical applications performed within these models. A set of dedicated simulations were presented in [18]. Moreover, the capabilities of FDS+Evac on the tunnel Lucivna in the Slovak Republic were studied in [51]. The results represent the impacts of fire on users' evacuation and the tunnel structure. According to the prof of the capability of FDS+Evac as mentioned above, this model is used in this study to simulate the evacuation process in a sample tunnel. Simulation of people's evacuation at $124,176,183$, and $344 \mathrm{~s}$ when $100 \mathrm{MW}$ fire located at the middle of the tunnel, was shown in Figure 3. The blue obstacles are passenger cars, the red ones are vans and the green ones are HGVs. The difference between figures at 124, 176, 183, and $344 \mathrm{~s}$ is evacuees' location, who were shown blue points along the evacuation route. According to studies that have been carried out in the field of people evacuation in tunnel fire scenarios, several parameters including position and accessibility of evacuation exits, location of the fire source, as well as the fire and smoke spread affected by ventilation system influence significantly on the total evacuation time. Although, further experimental testing and numerical simulation by available evacuation models for practical problems in tunnel fire 
safety are needed $[18,40,52,53]$. Figure 4 illustrates a graphical view of evacuees inside the tunnel at $88 \mathrm{~s}$ (first scenario).
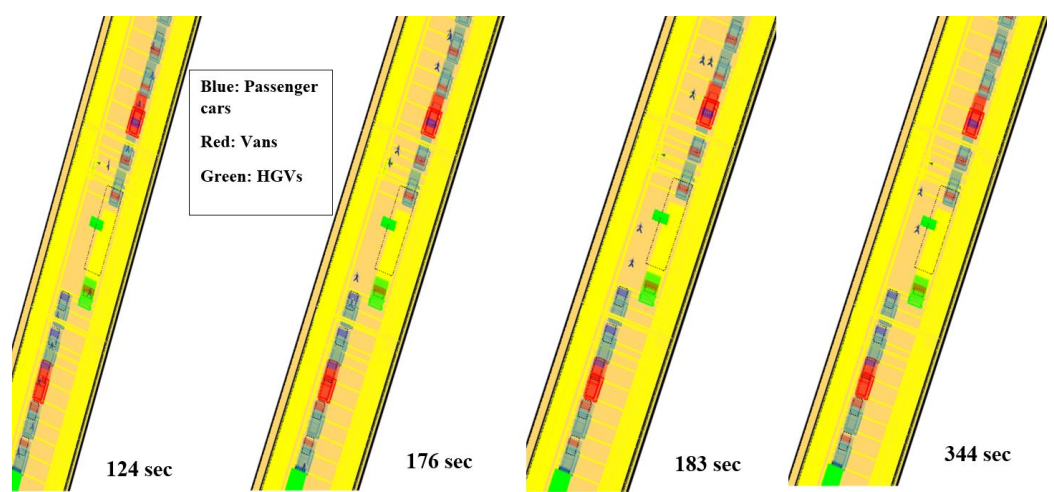

Figure 3. Evacuation progress views from left to right at 124 s, 176 s, 183 s and 344 s.

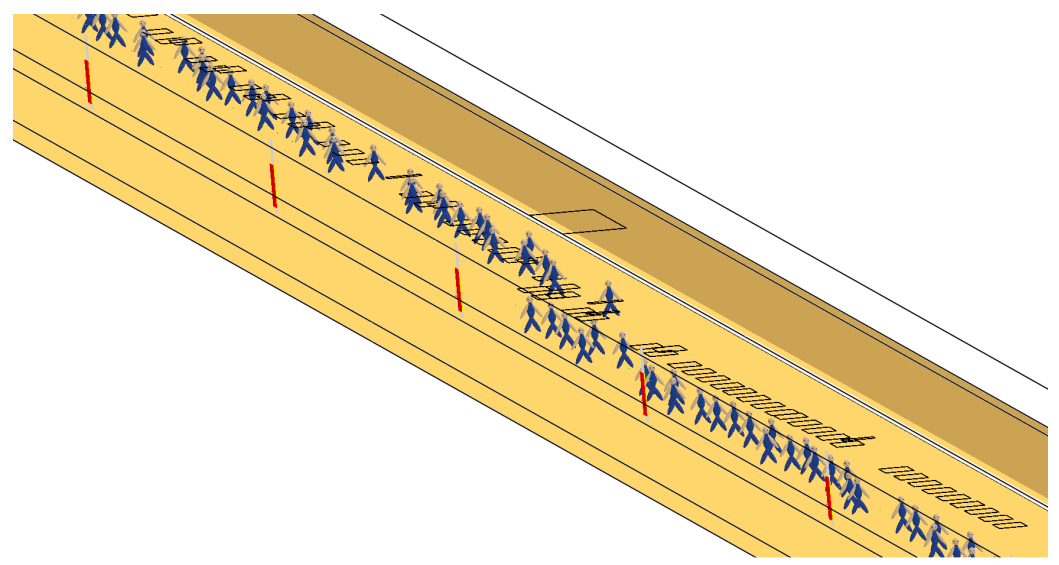

Figure 4. Graphical view of evacuees inside the tunnel at $88 \mathrm{~s}$.

A $150 \mathrm{~s}$ time delay including the detection time and the pre-movement time is considered. Drivers are evenly distributed in individual cars. The time dependence of the number of people evacuated through exits 1-16, leave the tunnel, derived from the results of evacuation simulation is shown in Figure 5. The evacuation simulation demonstrates that for these fire scenarios plus evacuation scenarios (size of the fire, fire location, geometry of tunnel, number of evacuees, and their distribution) all agents can leave the tunnel safely before the fire and its toxic products cause asphyxiation. Figure 5 shows the progress of the evacuation in time from the start of the fire for scenario 1.

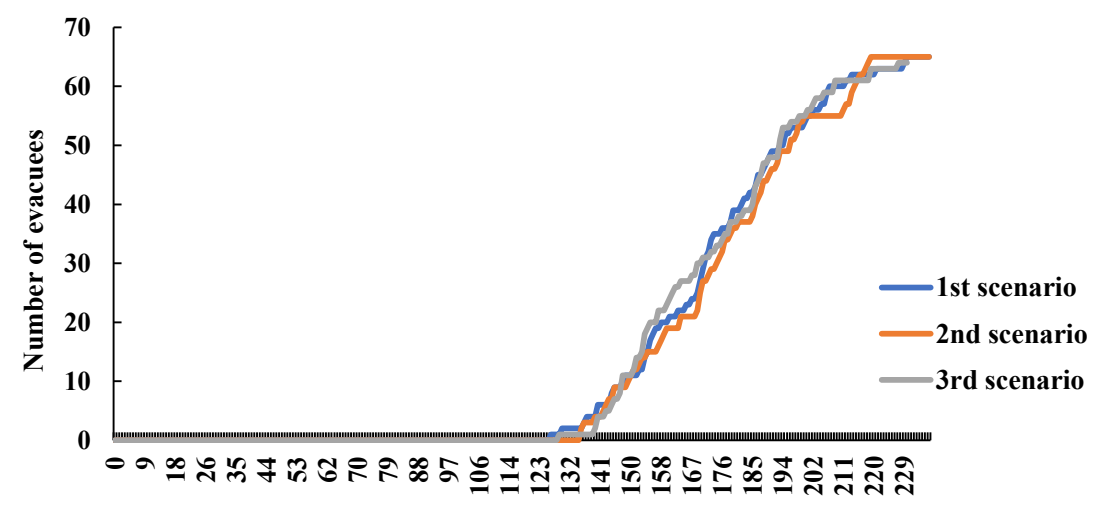

t (s)

Figure 5. Evacuation progress 1. 
Evacuation simulation results derived via FDS+Evac show that the evacuation process starts at $125 \mathrm{~s}$ and ends before $300 \mathrm{~s}$ (Figure 5) at all scenarios. As time goes on, the number of users inside the tunnel decreases steadily. It indicates that the width of the evacuation routes is sufficient. The evacuation time, which is a sum of pre-movement time and movement time, is a function of the distribution and travel speed of the evacuees as passengers' walking speed affects the movement time. The walking speed is $1.25 \pm 0.30 \mathrm{~m} / \mathrm{s}$ and its distribution is uniform. Evacuees start to evacuate before the sum of detection time and pre-movement time (150) because the local smoke concentration is used in the evacuation process to trigger the detection of a fire. A trigger was put in place whereby if a tunnel user experienced a smoke density of $17.24 \mathrm{mg} / \mathrm{m}^{3}$, then they would begin to evacuate $150 \mathrm{~s}$ after. During this time people may help family members (for example) or gathering small belongings. A smoke density of $17.24 \mathrm{mg} / \mathrm{m}^{3}$ represented a visibility distance of $100 \mathrm{~m}$ to walls, doors and a non-illuminated, reflective sign inside the tunnel. The sufficient width of the evacuation route results in a steady decrease in the number of evacuees with time.

In FDS+Evac, an optimization problem is solved by the exit selection algorithm to minimize the evacuation time considering the agent's walking time and queuing. The occupants' decision-making process is influenced by how much agents are familiar with emergency exits, smoke and combustion products effects, and the visibility of emergency exits. One of the main positive features of FDS+Evac is the interaction between fire and evacuation simulation which provides direct access of Evac to the fire simulation results. 3D fire simulation obtained from 3D simulation calculated on a 3D computational meshes with 2D evacuation simulation calculated on a 2D computational mesh are combined in FDS+Evac. The lack of experimental data is evident for deterministically calibrating the usage of emergency exits in relation to the type of exit layout. This issue has been fully investigated in [54] where the predictive capabilities of evacuation models had been used to predict the impact of exit signs on emergency exit usage. In this simulation, all emergency exits are modeled by the keyword EXIT (one of the FDS namelists) in the model. The EXIT models a real exit that is used to get out of the tunnel, when there is fire. So, it must have the EXIT marks that are needed by the local legislation. Therefore, as mentioned in our FDS+Evac simulation, the EXIT namelist contains this EXIT-SIGN keyword. This means the agents know all emergency doors because exit signs are lit all the time. The width of each emergency exit is $1.2 \mathrm{~m}$ and its height is $2.4 \mathrm{~m}$. Owing to the uneven distribution of people in two lanes and different distances from the emergency exits, the number of people using these emergency exits is different exit by exit. The number of people evacuated through exits No. 1 to No. 12 in scenarios 1, 2, and 3 is shown in Figure 6. As it is clear from Figure 6 the emergency exits used in scenarios 1 and 3 (Up-Left \& Down) are different from the exits used in scenario 2 (Up-Right) because of the different fire source location. For example, zero evacuees use emergency exit No. 1 when $100 \mathrm{MW}$ fire is located in the middle of the tunnel while eight evacuees use emergency exit No. 1 for $100 \mathrm{MW}$ fire close the tunnel portal. The choice of emergency exit depends on the walking distance between vehicles and exits, the smoke concentration affecting walking speed, the position and accessibility of evacuation exits. In a tunnel fire scenario, various factors could influence the tenable conditions inside the tunnel. These dangerous factors are caused by toxic and hot fumes as well as radiation and result in impaired escape, incapacitation, or even death due to asphyxiation, hyperthermia, or severe burns. 


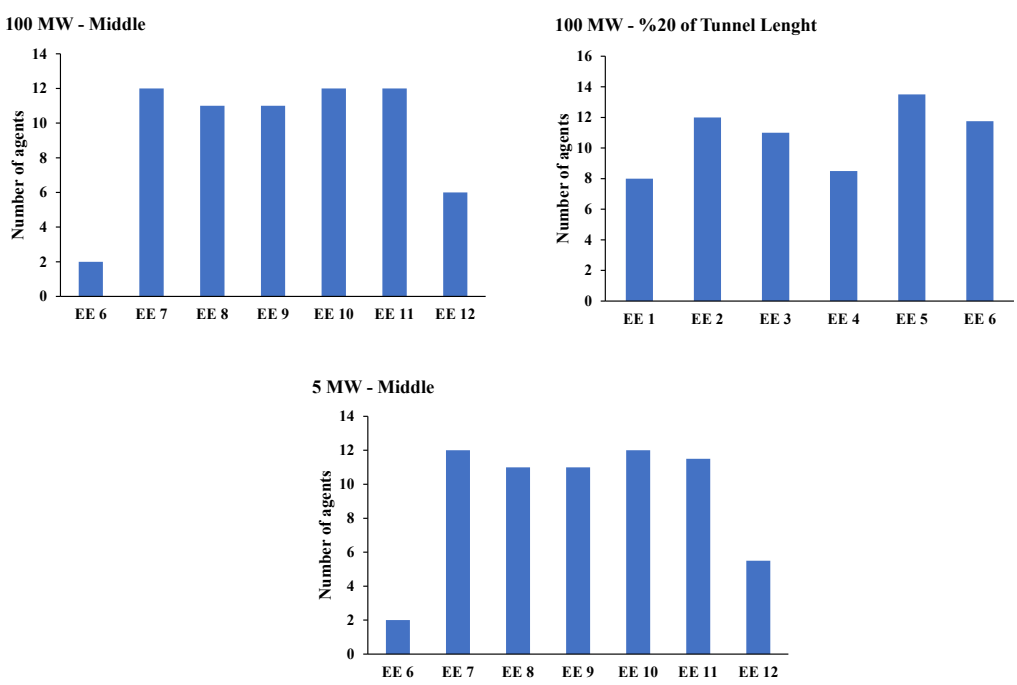

Figure 6. The number of people evacuated through exits No. 6 to No. 12.in $100 \mathrm{MW}$ fire and $5 \mathrm{MW}$ fire in the middle of the tunnel and through exits NO.1 to NO.12 in $100 \mathrm{MW}$ fire in the $20 \%$ of the tunnel length.

In this simulation, FDS results in terms of visibility, and FED along the egress path are recorded to evaluate the risk of fire and its combustion products on the evacuation process. By means of FDS, visibility is measured at the height of $1.8 \mathrm{~m}$ above the level of the walkway. A time sequence of visibility at passengers' head level in the first scenario at $38 \mathrm{~m}, 96 \mathrm{~m}$, and $1107 \mathrm{~m}$ downstream the fire source is shown in Figure 7. It can be seen that visibility changes suddenly from $30 \mathrm{~m}$ initially to $10 \mathrm{~m}$ at $130 \mathrm{~s}, 38 \mathrm{~m}$ from the fire source. This sudden decrease in comparison to visibility measured upstream the fire source is due to the tunnel slope and wind which causes asymmetric smoke emission. The effects of buoyancy due to tunnel gradient and backlayering are pronounced ([55]) and the importance of fire source location should not be neglected [31]. In addition, visibility results of a passenger car fire in the middle of the tunnel show that the visibility at human's height remains $30 \mathrm{~m}$ in most of the evacuation route and it does not decrease which shows the lower amount of smoke produced in this scenario.

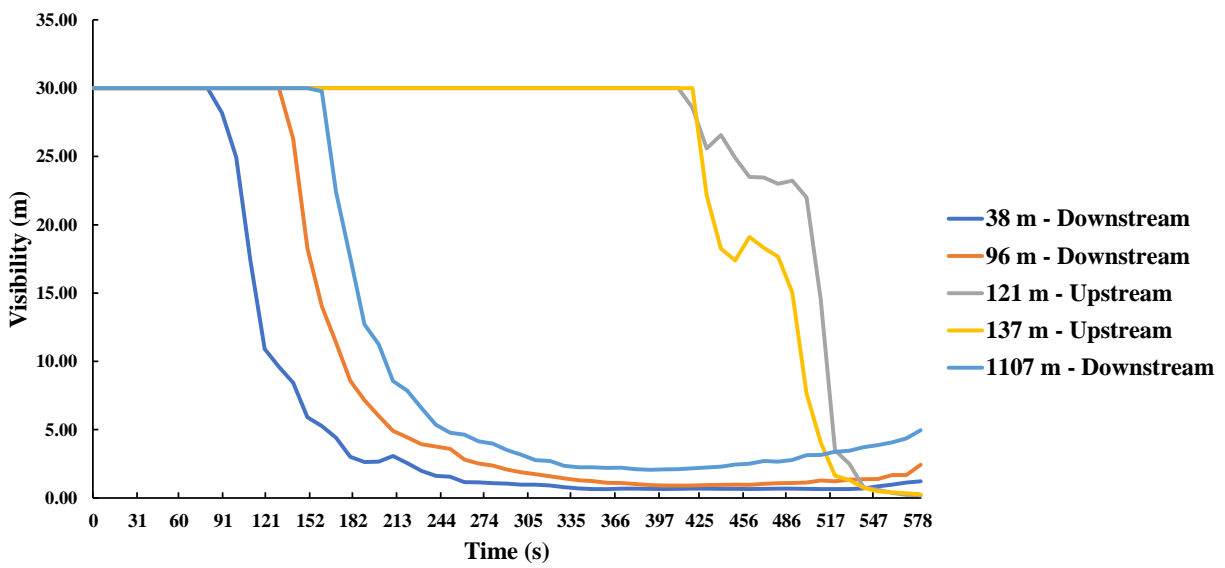

Figure 7. Soot visibility vs time at passengers' head level at 38 m, 96 m, and $1107 \mathrm{~m}$ downstream, and $121 \mathrm{~m}, 137 \mathrm{~m}$ upstream the fire source-1st scenario.

FDS+Evac program uses a concept of fractional effective dose, called FED, to determine the human response to toxic exposure Equation (5). Agents are presumed 'dead' when FED becomes 1, i.e., it has been exposed to a lethal dose of noxious substances. Figure 8 shows the amount of fractional effective dose at the human's height in the first scenario. According to this graph, none of the evacuees experiences a lethal or near-lethal exposure. 
The FED barely reached 1 of lethal level within the first $310 \mathrm{~s}$. FDS point measurements of the gas concentrations and FED are placed at the position of the agent. Figure 8 presents the maximum FED value among the agents which are alive at a given time. In other words, as a human is trapped in a spaced filled with smokes, once he/she gets out, within a few seconds, the toxicity in the body is also reduce because our body quickly removes the toxicity as we breathe fresh air. However, the FED increased quite violently from $310 \mathrm{~s}$ to $355 \mathrm{~s}$ to 0.06 at $355 \mathrm{~s}$ indicating increasing toxic gasses accumulations. The duration of exposure and concentration of noxious gases influenced on FED and when these two parameters, which are directly dependent on fire load, increase, FED increases. When all the evacuees leave the tunnel safely at $355 \mathrm{~s}$ and are no longer included in the simulation, the FED curve decreases sharply. Comparison between results in Figure 8 and the smoke distribution in Figure 9 confirms that the growing smoke layer corresponds with the increase in FED. As can be seen in Figure 9, dense smoke quickly formed along the tunnel and after a certain distance from the fire source, the smoke stratification changes, and the stably stratified zone becomes shorter.

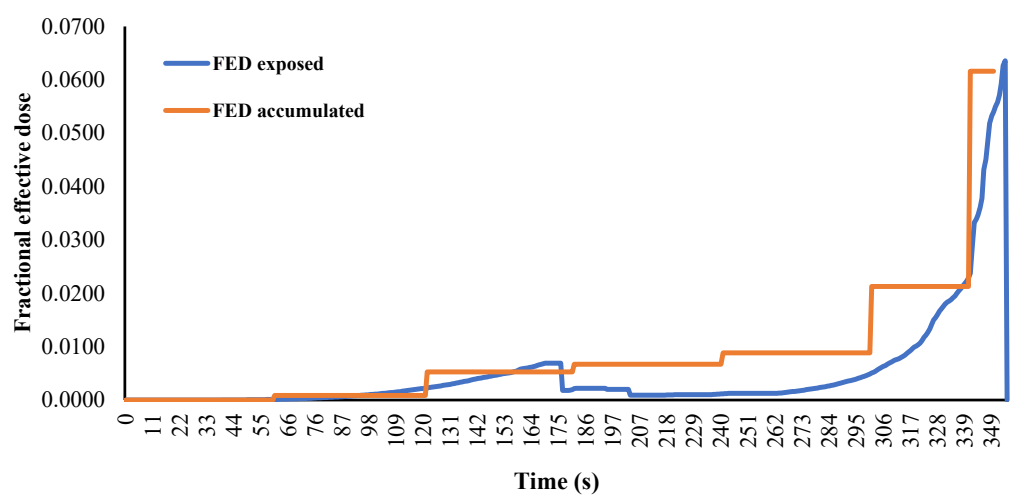

Figure 8. The amount of fractional effective dose at the human's height.

The pictures of smoke propagation show an asymmetrical distribution of the fire source. The variation of backlayering length during the fire is illustrated in Figure 9. This asymmetrical distribution is due to the tunnel inclination and the fire source location. For sloping tunnels, the stack effect results in a faster spread of smoke along the uphill direction of the tunnel. On the other hand, a slow spread of smoke with a short propagation length results along the downhill direction. In other words, gradients will make the smoke movement significantly different from that in a straight tunnel fire. As it is shown in Figure 9, the pictures of smoke flow are taken from uphill and downhill directions at $40,100,260$, and $400 \mathrm{~s}$. When the fire is located at the tunnel centre, the smoke shape is symmetrical and when the fire is located at an off-centre position, the physical phenomena become asymmetric about the tunnel center or the fire location. Moreover, Figure 10 shows asymmetry vortical shapes at the left and right sides of the fire source location. 


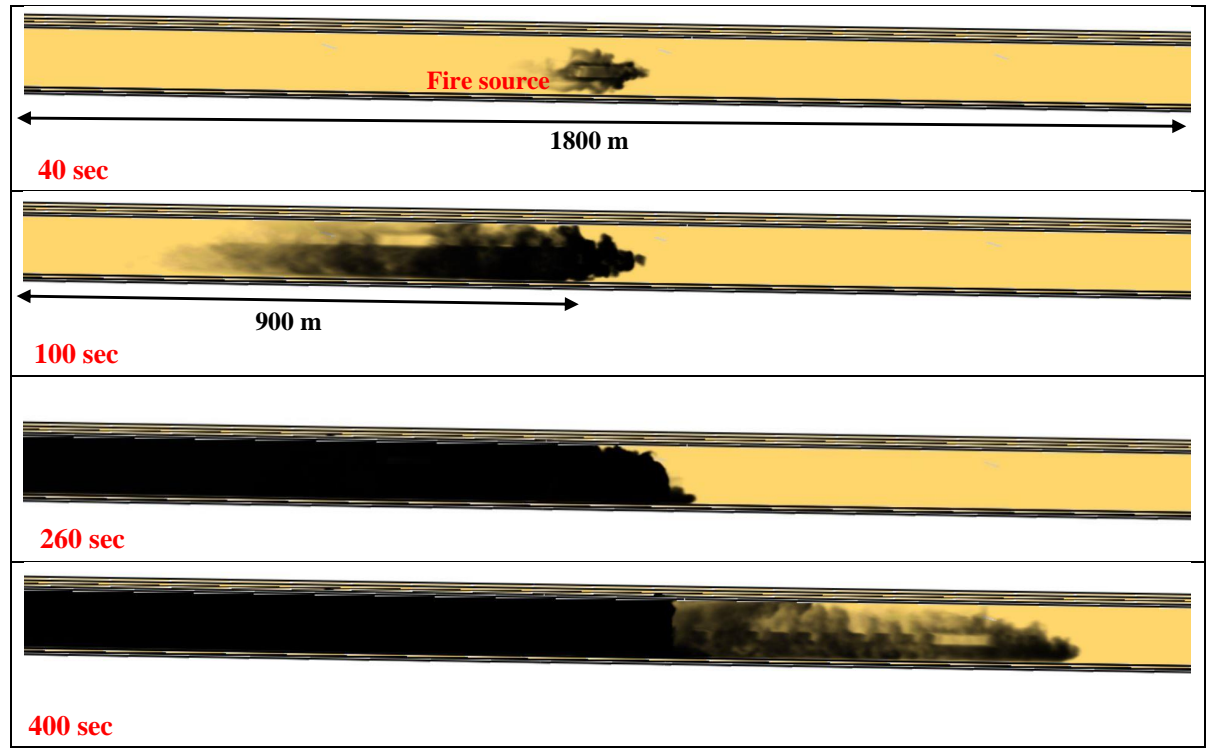

Figure 9. The asymmetrical smoke propagation at 40,100,260, and $400 \mathrm{~s}$ due to tunnel inclination and fire source location.

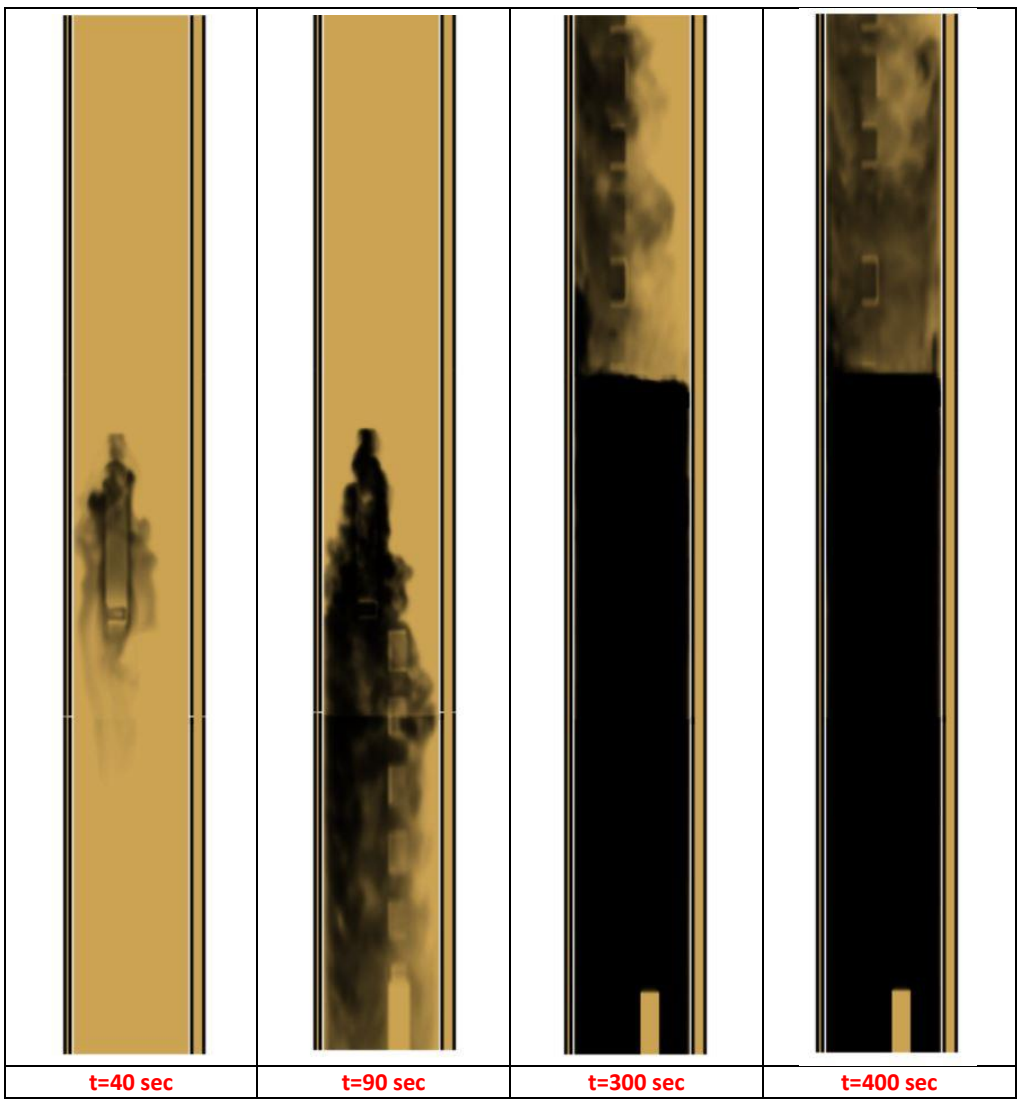

Figure 10. The upside smoke distribution at 40, 90, 300, and $400 \mathrm{~s}$.

\section{Conclusions}

The demand for the assessment of occupants' evacuation process in road tunnels was the motivation behind this study. The fire sources are an HGV and a passenger car. The first scenario, which is the worse fire scenario in road tunnels, is a 100 MW fire positioned in the middle of the tunnel. Both lanes are congested in contraflow mode and as evacuees are simulated inside vehicles, they should escape from their vehicles. Therefore, they have 
to abandon their cars and walk along sidewalks in the direction of the emergency exits. FDS+Evac model is used to study the impact of the occurrence of 100 MW and 5 MW fires at various locations on people evacuation in a $1.8 \mathrm{~km}$ long tunnel under contraflow condition. FDS+Evac is based on a CFD fire model which is combined with the people evacuation model based on agent principle. Evac utilizes the relevant modeling results obtained via FDS simulation to model the effects of fire and smoke on the evacuation process. Two traffic lanes are described, in which 32 and 34 vehicles are considered. The complete geometry of this emergency scenario is built, including distribution of vehicles along the tunnel, smoke generation, and location of the emergency exits. It is expected that when the location of the fire source changed, people use different emergency locations. This is correctly simulated via FDS+Evac (Figure 4). The numerical results of the worst-case scenario show that the mean of the total evacuation time is $355 \mathrm{~s}$ and all evacuees can leave the tunnel before survival thresholds exceed the tolerable limits. Despite most of the straight tunnel geometries are kept symmetrical about a horizontal centreline (looking from the side), the horizontal smokes propagation becomes asymmetrical due to any slight gradient or flowing airs. This is because of backlayering event [55]. It is concluded from the numerical results of this research that if the ventilation system is turned off in the contraflow condition in the tunnel under consideration, and selected scenarios, people will not be in danger and can evacuate safely. Further investigations related to the impact of different fire source locations, more than one evacuee in each vehicle, and individual evacuees' behaviour of their group bonding in case of fire will be needed.

\section{Ongoing Research Work}

Future investigations related to evacuees' diversity as well as traffic composition of one of the UK road tunnels will be carried out with more up-to-date information.

Author Contributions: R.K. undertook the main works comprising of confirmation of geometry, meshing, simulations and analysis. L.F. and J.A. provided supervisory and advice on the use of software and approvals of such analysis. Z.H. provided the techniques and presentation of the works into an academic article, grants. All authors have read and agreed to the published version of the manuscript.

Funding: This research was funded by National University of Malaysia grant number GUP-2020-015.

Acknowledgments: We would like to appreciate research grant provided by UKM's GUP-2020-015 and London Bridge Associates Ltd.

Conflicts of Interest: The authors declare no conflict of interest.

\section{References}

1. Lovreglio, R.; Ronchi, E.; Borri, D. The validation of evacuation simulation models through the analysis of behavioural uncertainty. Reliab. Eng. Syst. Saf. 2014, 131, 166-174. [CrossRef]

2. Ronchi, E.; Reneke, P.A.; Peacock, R.D. A method for the analysis of behavioural uncertainty in evacuation modelling. Fire Technol. 2014, 50, 1545-1571. [CrossRef]

3. Kuligowski, E.D.; Peacock, R.D.; Hoskins, B.L. A Review of Building Evacuation Models; US Department of Commerce, National Institute of Standards and Technology: Gaithersburg, MD, USA, 2005.

4. Ronchi, E. Testing the predictive capabilities of evacuation models for tunnel fire safety analysis. Saf. Sci. 2013, 59, 141-153. [CrossRef]

5. Lovreglio, R.; Ronchi, E.; Nilsson, D. A model of the decision-making process during pre-evacuation. Fire Saf. J. 2015, 78, 168-179. [CrossRef]

6. Lovreglio, R.; Ronchi, E.; Nilsson, D. An Evacuation Decision Model based on perceived risk, social influence and behavioural uncertainty. Simul. Model. Pract. Theory 2016, 66, 226-242. [CrossRef]

7. Lovreglio, R.; Fonzone, A.; dell'Olio, L.; Borri, D. A study of herding behaviour in exit choice during emergencies based on random utility theory. Saf. Sci. 2016, 82, 421-431. [CrossRef]

8. Lovreglio, R.; Fonzone, A.; dell'Olio, L. A mixed logit model for predicting exit choice during building evacuations. Transp. Res. Part A Policy Pract. 2016, 92, 59-75. [CrossRef]

9. Lovreglio, R.; Ronchi, E.; Maragkos, G.; Beji, T.; Merci, B. A dynamic approach for the impact of a toxic gas dispersion hazard considering human behaviour and dispersion modelling. J. Hazard. Mater. 2016, 318, 758-771. [CrossRef] [PubMed] 
10. Fridolf, K.; Ronchi, E.; Nilsson, D.; Frantzich, H. Movement speed and exit choice in smoke-filled rail tunnels. Fire Saf. J. 2013, 59, 8-21. [CrossRef]

11. Haddad, R.K.; Rasani, M.R.; Harun, Z. Fire-Induced Flow Temperature Distribution Beneath a Ceiling. J. Kej. 2020, 32, 247-257.

12. Bari, S.; Naser, J. Simulation of smoke from a burning vehicle and pollution levels caused by traffic jam in a road tunnel. Tunn. Undergr. Space Technol. 2005, 20, 281-290. [CrossRef]

13. Hu, L.; Fong, N.K.; Yang, L.; Chow, W.K.; Li, Y.; Huo, R. Modeling fire-induced smoke spread and carbon monoxide transportation in a long channel: Fire dynamics simulator comparisons with measured data. J. Hazard. Mater. 2007, 140, 293-298. [CrossRef]

14. Ji, J.; Fan, C.; Zhong, W.; Shen, X.; Sun, J. Experimental investigation on influence of different transverse fire locations on maximum smoke temperature under the tunnel ceiling. Int. J. Heat Mass Transf. 2012, 55, 4817-4826. [CrossRef]

15. McGrattan, K.; Hamins, A. Numerical simulation of the Howard street tunnel fire. Fire Technol. 2006, 42, 273-281. [CrossRef]

16. Yang, G.S.; Peng, L.M.; Zhang, J.H.; An, Y.L. Simulation of people's evacuation in tunnel fire. J. Cent. South Univ. Technol. 2006, 13, 307-312. [CrossRef]

17. Kučera, P.; Bradáčová, I. Modelling the evacuation of people from a train on fire in a railway tunnel. In Recent Advances in Engineering, Proceedings of the 3rd European Conference of Civil Engineering, Paris, France, 2-4 December 2012; WSEAS Press: Paris, France, 2012; pp. 196-201.

18. Ronchi, E.; Colonna, P.; Capote, J.; Alvear, D.; Berloco, N.; Cuesta, A. The evaluation of different evacuation models for assessing road tunnel safety analysis. Tunn. Undergr. Space Technol. 2012, 30, 74-84. [CrossRef]

19. Ronchi, E.; Gwynne, S.M.; Purser, D.A.; Colonna, P. Representation of the impact of smoke on agent walking speeds in evacuation models. Fire Technol. 2013, 49, 411-431. [CrossRef]

20. Haddad, R.K.; Reda, E.; Rasani, M.R.; Zedan, C.M.; Harun, Z. Fire simulation of a scaled mass rapid transit (MRT) tunnel. J. Mech. Eng. 2016, SI7, 1-18.

21. Lee, S.R.; Ryou, H.S. A numerical study on smoke movement in longitudinal ventilation tunnel fires for different aspect ratio. Build. Environ. 2006, 41, 719-725. [CrossRef]

22. Guo, X.; Zhang, Q. Analytical solution, experimental data and CFD simulation for longitudinal tunnel fire ventilation. Tunn. Undergr. Space Technol. 2014, 42, 307-313. [CrossRef]

23. Carvel, R.O.; Rein, G.; Torero, J.L. Ventilation and suppression systems in road tunnels: Some issues regarding their appropriate use in a fire emergency. ERA 2009, 2, 375-382.

24. Halawa, T. Numerical simulation of the evacuation process and smoke propagation due to a fire in a road tunnel with transverse ventilation system. J. Therm. Sci. Eng. Appl. 2021, 13, 031015. [CrossRef]

25. Guo, X.; Pan, X.; Wang, Z.; Yang, J.; Hua, M.; Jiang, J. Numerical simulation of fire smoke in extra-long river-crossing subway tunnels. Tunn. Undergr. Space Technol. 2018, 82, 82-98. [CrossRef]

26. Burstedde, C.; Klauck, K.; Schadschneider, A.; Zittartz, J. Simulation of pedestrian dynamics using a two-dimensional cellular automaton. Phys. A Stat. Mech. Its Appl. 2001, 295, 507-525. [CrossRef]

27. Helbing, D.; Farkas, I.; Vicsek, T. Simulating dynamical features of escape panic. Nature 2000, 407, 487-490. [CrossRef]

28. Lei, W.; Li, A.; Gao, R.; Wang, X. Influences of exit and stair conditions on human evacuation in a dormitory. Phys. A Stat. Mech. Its Appl. 2012, 391, 6279-6286. [CrossRef]

29. Lei, W.; Li, A.; Gao, R. Effect of varying two key parameters in simulating evacuation for a dormitory in China. Phys. A Stat. Mech. Its Appl. 2013, 392, 79-88. [CrossRef]

30. Yamamoto, K.; Sawaguchi, Y.; Nishiki, S. Simulation of tunnel fire for evacuation safety assessment. Safety 2018, 4, 12. [CrossRef]

31. Haddad, R.; Zulkifli, R.; Maluk, C.; Harun, Z. Experimental Investigation on the Influences of Different Horizontal Fire Locations on Smoke Temperature Stratification under Tunnel Ceiling. J. App. Flu. Mec 2020, 13, 1289-1298.

32. Haddad, R.K.; Harun, Z.; Maluk, C.; Rasani, M.R. Experimental study of the influence of blockage on critical velocity and backlayering length in a longitudinally ventilated tunnel. JP J. Heat Mass Transf. 2019, 17, 451-476. [CrossRef]

33. McGrattan, K.B.; Baum, H.R.; Rehm, R.G.; Hamins, A.; Forney, G.P.; Floyd, J.E.; Hostikka, S.; Prasad, K. Fire Dynamics SimulatorTechnical Reference Guide; National Institute of Standards and Technology, Building and Fire Research: Gaithersburg, MD, USA, 2000.

34. McGrattan, K.; Forney, G. Fire Dynamics Simulator-User's Manual, National Institute of Standards and Technology. NIST Spec. Publ. 2004. [CrossRef]

35. Korhonen, T.; Hostikka, S. FDS + Evac-Technical Reference + User's Guide; VTT Technical Research Centre of Finland: Espoo, Finland, 2007.

36. Helbing, D.; Molnar, P. Social force model for pedestrian dynamics. Phys. Rev. E 1995, 51, 4282. [CrossRef] [PubMed]

37. Werner, T.; Helbing, D. The social force pedestrian model applied to real life scenarios. Pedestrian and Evacuation Dynamics 2003. In Proceedings of the 2nd International Conference on Pedestrian and Evacuation Dynamics, Greenwich, UK, 20-22 August 2013; CMS Press: Kottayam, India, 2003; pp. 17-26.

38. Purser, D.A. Modelling toxic and physical hazard in fire. Fire Saf. Sci. 1989, 2, 391-400. [CrossRef]

39. Kevin, M.; Bryan, K.; Simo, H.; Jason, F. Fire dynamics simulator (Version 5) user's guide. NIST Spec. Publ. $2007,1019,1-81$.

40. Korhonen, T.; Hostikka, S. Fire Dynamics Simulator with Evacuation: FDS + Evac: Technical Reference and User's Guide; VTT Technical Research Centre of Finland: Espoo, Finland, 2009. 
41. Purser, D.; Grimshaw, P. The incapacitative effects of exposure to the thermal decomposition products of polyurethane foams. Fire Mater. 1984, 8, 10-16. [CrossRef]

42. Luft, U.C. Aviation physiology-the effects of altitude. Handb. Physiol. 1965, 2, 1099-1145.

43. Kimmerle, G.; Bayer-Aktiengesellschaft, L. Aspects and Methodology for the Evaluation of Toxicological Parameters during Fire Exposure; The University of Utah: Salt Lake City, UT, USA, 1974.

44. King, B. High concentration-short time exposures and toxicity. J. Ind. Hyg. Toxicol. 1949, 31, 365-75.

45. Schulte, J.H. Sealed environments in relation to health and disease. Arch. Environ. Heal. Int. J. 1964, 8, 438-452. [CrossRef] [PubMed]

46. Castleman, B.I.; Ziem, G.E. American conference of governmental industrial hygienists: Low threshold of credibility. Am. J. Ind. Med. 1964, 26, 133-143. [CrossRef] [PubMed]

47. McGrattan, K.; Hostikka, S.; McDermott, R.; Floyd, J.; Weinschenk, C.; Overholt, K. Fire dynamics simulator user's guide. NIST Spec. Publ. 2013, 1019, 1-339.

48. Ingason, H.; Lönnermark, A. Heat release rates from heavy goods vehicle trailer fires in tunnels. Fire Saf. J. 2005, 40, 646-668. [CrossRef]

49. Cheong, M.; Spearpoint, M.; Fleischmann, C. Using the peak heat release rate to determine the fire risk level of road tunnels. Proc. Inst. Mech. Eng. Part O J. Risk Reliab. 2008, 222, 595-604. [CrossRef]

50. Babrauskas, V. Book Review: SFPE Handbook of Fire Protection Engineering. J. Fire Sci. 2016, 34, 164-167. [CrossRef]

51. Mozer, V. Modelling fire severity and evacuation in tunnels. Commun.-Sci. Lett. Univ. Zilina 2013, 15, 85-90.

52. Murray-Smith, D.J. Testing and Validation of Computer Simulation Models; Springer: Cham, Switzerland, 2015; Volume 10. ISBN 978-3-319-15099-4.

53. McGrattan, K.B.; Forney, G.P.; Floyd, J.; Hostikka, S.; Prasad, K. Fire Dynamics Simulator (Version 5): User's Guide; National Institute of Standards and Technology NIST: Gaithersburg, MD, USA, 2007.

54. Ronchi, E.; Nilsson, D.; Gwynne, S. Modelling the impact of emergency exit signs in tunnels. Fire Technol. 2012, 48, 961-988. [CrossRef]

55. Haddad, R.K.; Maluk, C.; Reda, E.; Harun, Z. Critical velocity and backlayering conditions in rail tunnel fires: state-of-the-art review. J. Combust. 2019, 2019. [CrossRef] 